\title{
Tratamiento biológico de aguas residuales en reactor anaerobio de flujo ascendente de empresa productora de grenetina
}

\section{Biological treatment of wastewater in an upflow anaerobic sludge blanket reactor of flavorless jelly facility}

BALDERAS-SALAS, Perla Sofia †ै, CORDOBA-CASTRO, Andrea Leticia, PÁRAMO-VARGAS Javier* y MURILLO-HERNÁNDEZ, Martha Betzabé

Universidad Tecnológica de León. Sustentabilidad para el Desarrollo. Ingeniería en Tecnología Ambiental.

ID $1^{\mathrm{er}}$ Autor: Perla Sofia, Balderas-Salas / ORC ID: 0000-0002-8658-278X, CVU CONACYT ID: 1002985

ID $1^{\mathrm{er}}$ Coautor: Andrea Leticia, Cordoba-Castro / ORC ID: 0000-0002-8075-1239, CVU CONACYT ID: 997689

ID $2^{\text {do }}$ Coautor: Martha Betzabé, Murillo-Hernández / ORC ID: 0000-0001-9146-1125, CVU CONACYT ID: 521401

ID $3^{\text {er }}$ Coautor: Javier, Páramo-Vargas / ORC ID: 0000-0003-4022-7050, CVU CONACYT ID: 66460

DOI: $10.35429 / J T I P .2019 .7 .3 .17 .24$

Recibido 03 de Abril, 2019; Aceptado 09 Junio, 2019

\section{Resumen}

Los reactores anaerobios de una empresa productora de grenetina; tenían una baja eficiencia en el tratamiento de su agua residual, con aproximadamente el $12 \%$ de remoción de DQO; por esta razón se evaluó su funcionamiento, mediante un reactor a escala piloto, usando como inóculo, lodo proveniente del tratamiento de agua residual de una empresa similar, con una AME promedio de 0.115 $\mathrm{gDQO} / \mathrm{gSSV} \cdot \mathrm{d}$. Se trabajó con una concentración inicial de $35 \mathrm{kgSSV} / \mathrm{m}^{3}$ del inóculo, una carga orgánica promedio de $2.6843 \mathrm{kgDQO} / \mathrm{m}^{3} \cdot \mathrm{d}$ y agua residual con DQO de $6797 \mathrm{mg} / \mathrm{L}$ y nitrógeno total de $1213 \mathrm{mg} / \mathrm{L}$. El flujo de alimentación fue de 0.264 $\mathrm{L} / \mathrm{h}$, con la finalidad de obtener un tiempo de retención hidráulico de $27.14 \mathrm{~h}$, igual al del reactor de la empresa. Se logró una remoción promedio de DQO del $65.24 \%$. Los resultados presentaron concentraciones de sulfuros de $461.4 \mathrm{mg} / \mathrm{L} \mathrm{y}$ nitrógeno amoniacal de $1054.4 \mathrm{mg} / \mathrm{L}$; que no resultaron inhibitorias.

Tratamiento anaerobio, Sólidos suspendidos, Biológico

\begin{abstract}
The anaerobic reactors of a flavorless jelly producing company; had a low efficiency in the treatment of their wastewater, with approximately $12 \%$ of COD removal. For this reason, it's operation was evaluated, in a pilot scale reactor, using as inoculum, sludge from the wastewater treatment of a similar facility, with an average Specific Methanogenic Activity of $0.115 \mathrm{~g} \mathrm{COD} / \mathrm{gSSV}$.d. We worked with an initial concentration of $35 \mathrm{kgSSV} / \mathrm{m}^{3}$ of the inoculum, an average organic load of 2.6843 $\mathrm{kgCOD} / \mathrm{m}^{3} \mathrm{~d}$ and wastewater with COD of 6797 $\mathrm{mg} / \mathrm{L}$ and total nitrogen of $1213 \mathrm{mg} / \mathrm{L}$. The feed flow was $0.264 \mathrm{~L} / \mathrm{h}$, in order to obtain an hydraulic retention time of $27.14 \mathrm{~h}$, equal to the value of the reactor of the company. An average COD removal of $65.24 \%$ was achieved. The results showed sulphide concentrations of $461.4 \mathrm{mg} / \mathrm{L}$ and ammonium nitrogen of $1054.4 \mathrm{mg} / \mathrm{L}$; that were not inhibitory.
\end{abstract}

Anaerobic treatment, Suspended solids, Biological

Citación: BALDERAS-SALAS, Perla Sofia, CORDOBA-CASTRO, Andrea Leticia, PÁRAMO-VARGAS Javier y MURILLO-HERNÁNDEZ, Martha Betzabé. Tratamiento biológico de aguas residuales en reactor anaerobio de flujo ascendente de empresa productora de grenetina. Revista de Tecnologías en Procesos Industriales. 2019. 3-7: 17-24

\footnotetext{
* Correspondencia del Autor (jparamo@utleon.edu.mx)

$\dagger$ Investigador contribuyendo como primer autor.
} 


\section{Introducción}

El cuidado del agua es una necesidad creciente, de la mano al incremento de la población, lo cual demanda cada vez más recursos naturales y la atención de sus necesidades, genera problemas ambientales (Torres, 2012). En México, como en otros países, el cuidado del agua es importante, pues 105 acuíferos están sobreexplotados (CNA, 2017; CNA, 2018); siendo la región hidrológica a que corresponde el estado de Guanajuato, una de las de mayor grado de presión sobre el recurso agua, con un 45.4\% (CNA, 2017). En países como México, de clima tropical, es común el uso del tratamiento anaerobio, usando por ejemplo reactores anaerobios de lecho ascendente (RAFA), capaces de remover del 85 al $90 \%$ de la DQO; adecuados para aguas residuales con alta carga contaminante; como es el caso de la industria productora de grenetina.

En la empresa donde se realizó este proyecto, el proceso de producción de grenetina, genera gran cantidad de agua residual con alto contenido orgánico, como lo indican los valores de demanda bioquímica de oxígeno $\left(\mathrm{DBO}_{5}\right)$ de $3295.97 \mathrm{mg} / \mathrm{L}$ y demanda química de oxígeno (DQO) promedio de $6797.28 \mathrm{mg} / \mathrm{L}$. El tratamiento del agua residual es de tipo biológico, constituido por una etapa anaerobia y una aerobia. En el año 2015, se elaboraron e implementaron propuestas de mejora en la operación, control y monitoreo de la planta de tratamiento de aguas residuales de la empresa y en el año 2016, se evaluó la etapa anaerobia del tren de tratamiento, donde se encontró una eficiencia de remoción de DQO del $36.67 \%$.

Se realizaron, además, pruebas de actividad metanogénica especifica (AME) y Potencial bioquímico del metano (PBM) (Torres Lozada \& Pérez, 2010). Estas pruebas permitieron cuantificar la producción de metano y establecer el grado de biodegradabilidad del sustrato e identificar efectos inhibitorios en el proceso (Parra Orobio, 2014). Los resultados mostraron que el lodo generado dentro de los reactores anaerobios de flujo ascendente (RAFA's) se componía principalmente por material inorgánico (Pachuca Guerra, 2015; Balderas Salas, 2016). Se usó también, lodo proveniente de una empresa productora de grenetina, similar en su proceso productivo y en el tren de tratamiento, al caso de estudio. En este caso la eficiencia de remoción de DQO obtenida fue de entre 70 y $75 \%$ (Balderas Salas, 2016).
En este proyecto se evaluó el tratamiento del agua residual de la empresa productora de grenetina, en un reactor piloto anaerobio de flujo ascendente, en régimen continuo; con el fin de obtener información para generar propuestas de mejora para los reactores de la planta real.

\section{Marco teórico}

El agua es uno de los recursos más importantes para la vida en el planeta y el hombre depende de su disponibilidad, no sólo para el consumo doméstico, sino también para el desarrollo de las actividades agrícolas e industriales. $\mathrm{Al}$ aumentar la demanda de este recurso, también se ha incrementado la generación de aguas residuales con mezclas complejas de compuestos orgánicos e inorgánicos. El vertido de aguas residuales sin un tratamiento previo, provoca la contaminación de las aguas en los cuerpos superficiales y subterráneos.

Esto representa un problema importante, ya que la presencia de estos contaminantes impide que el agua tenga la calidad necesaria para su reutilización, agravando el problema de escasez, elevando los costos de distribución y disposición del agua. Por lo referido, son necesarios los tratamientos de las aguas residuales; de los cuales, los físicos, pueden lograr hasta un $30 \%$ de remoción de la contaminación presente, mientras que los biológicos logran hasta un $95 \%$. Dependiendo de las condiciones del tratamiento biológico, será la transformación de los contaminantes; en condiciones aerobias, la materia orgánica es transformada principalmente en dióxido de carbono, agua y en condiciones anaerobias, se da la transformación a metano, dióxido de carbono.

El proceso anaerobio es un proceso usado en el tratamiento biológico de aguas residuales; en el que un consorcio microbiano convierte la materia orgánica en biogás (metano, 50 a $70 \%$, dióxido de carbono, 30 a $50 \%$, pequeñas cantidades de sulfuro de hidrógeno, mercaptano e hidrógeno), en ausencia de oxígeno. Son una opción viable para el tratamiento de aguas y lodos residuales debido a su bajo consumo de energía y su capacidad de tratar desechos con alta carga orgánica. El proceso comprende dos etapas: fermentación ácida, que es donde se lleva a cabo la hidrólisis y la acetogénesis, junto con la fermentación metanogénica, donde ocurre la acetogénesis y metanogénesis. 
Estas etapas involucran una serie de reacciones bioquímicas complejas, desarrolladas por bacterias anaerobias las cuales interactúan entre sí. En la etapa de fermentación ácida, los compuestos orgánicos complejos del agua residual (proteínas, grasas e hidratos de carbono) son hidrolizados en compuestos orgánicos más sencillos (aminoácidos, azúcares y ácidos grasos de cadena larga); por un grupo de bacterias anaerobias facultativas acidogénicas o fermentativas, las cuales tienen una velocidad de crecimiento más elevada que las bacterias metanogénicas responsables de la etapa de fermentación metanogénica.

Es por esto que la etapa de fermentación metanogénica controla la velocidad del proceso anaerobio (Rubens Sette Ramalho, 1996). En la etapa de fermentación metanogénica, las bacterias metanogénicas que son estrictamente anaerobias, convierten los ácidos de cadenas más largas a metano, dióxido de carbono y ácidos orgánicos de cadenas más cortas.

Entre los parámetros principales del proceso anaerobio están: a) Temperatura: se recomienda un valor óptimo de $35^{\circ} \mathrm{C}$, b) Acidez: el valor óptimo de $\mathrm{pH}$ oscila entre 6.6 y 7.6, pues existe un medio prácticamente neutro, apto para las bacterias metanogénicas, c) Contenido en sólidos: se suele operar en mejores condiciones con menos de un $10 \%$ de sólidos, lo que explica que la biomasa más adecuada sea la de alto contenido en humedad, d) Nutrientes: para el crecimiento y la actividad de las bacterias, éstas tienen que disponer de carbono, nitrógeno, fósforo, azufre y algunas sales minerales, compatibles con la cantidad de carbono y e) Tóxicos: presencia de compuestos en cantidades elevadas, que pueden transformarse en tóxicos durante el proceso, como $\mathrm{N}\left(\mathrm{NH}_{4}{ }^{+}, \mathrm{NH}_{3}\right), \mathrm{S}\left(\mathrm{S}^{2-}\right)$, oxígeno, detergentes y pesticidas, además de metales pesados, metales alcalinos y alcalinotérreos (Lorenzo Acosta \& Obaya Abreu, 2005).

La principal característica de un RAFA, además del flujo ascendente, es la formación de un manto de lodo floculento o granular con buena capacidad de sedimentación, en donde se realiza la actividad biológica. El biogás es colectado en la parte superior.
El tratamiento anaerobio de aguas residuales con reactores RAFA, es adecuado para aguas residuales de alta carga orgánica, como lo muestra el trabajo de Sosa Villalobos (2014), que con un tratamiento anaerobio por lotes, del agua residual de destilería de alcohol de caña, con una DQO total de 128.63 g/L, logró una remoción de 79 a $91 \%$ y el trabajo de Montoya et al. (2003), que lograron en el tratamiento anaerobio de aguas residuales municipales una remoción de DQO de hasta el $76 \%$.

\section{Materiales y métodos}

\section{Materiales y reactivos}

Se usó agua residual que se muestreaba a la entrada de la etapa anaerobia, 3 veces por semana. Se usaron principalmente los reactivos siguientes, biftalato de potasio $\left(\mathrm{C}_{8} \mathrm{H}_{5} \mathrm{KO}_{4}\right)$ marca MEYER, pureza 95-99\%; sulfato de plata $\left(\mathrm{Ag}_{2} \mathrm{SO}_{4}\right)$ marca MEYER, pureza $95 \%$; ácido sulfúrico concentrado $\left(\mathrm{H}_{2} \mathrm{SO}_{4}\right)$ marca MEYER, 95-98\% pureza; ácido clorhídrico concentrado (HCl) marca MEYER, pureza 90\%; dicromato de potasio $\left(\mathrm{K}_{2} \mathrm{Cr}_{2} \mathrm{O}_{7}\right)$ marca MEYER, pureza del 99\%; sulfato mercúrico $\left(\mathrm{HgSO}_{4}\right)$ marca MEYER, $98 \%$ de pureza; sulfato ferroso amoniacal hexahidratado $\left[\mathrm{Fe}\left(\mathrm{NH}_{4}\right)_{2}\left(\mathrm{SO}_{4}\right)_{2} \cdot 6 \mathrm{H}_{2} \mathrm{O}\right]$ marca MEYER, 98.5$100 \%$ de pureza; sulfato ferroso heptahidratado $\left(\mathrm{FeSO}_{4} \cdot 7 \mathrm{H}_{2} \mathrm{O}\right)$ marca KEM, 99\% pureza; permanganato de potasio $\left(\mathrm{KMnO}_{4}\right)$ marca $\mathrm{KEM}$, pureza del $99 \%$; clorhidrato de hidroxilamina $\left(\mathrm{NH}_{2} \mathrm{OH} \cdot \mathrm{HCl}\right)$ marca ALIT, pureza del 96\%; 1,10-fenantrolina monohidratada $\left(\mathrm{C}_{12} \mathrm{H}_{8} \mathrm{~N}_{2} \cdot \mathrm{H}_{2} \mathrm{O}\right)$ marca MEYER y agua destilada.

\section{Equipos}

En la determinación de la demanda química de oxígeno (DQO), se usó un reactor digestor marca $\mathrm{HACH}$. Para la determinación de sólidos se utilizó un horno y mufla marca FELISA. 


\section{Metodologías de análisis}

Para monitorear la eficiencia del tratamiento con el equipo piloto RAFA, se analizaron los parámetros de: sólidos (NMX-AA-036-SCFI2001), DQO (NMX-AA-030-2-SCFI-2011), DBO (NMX-AA-028-SCFI-2001), nitrógeno (NMX-AA-026-SCFI-2010), fósforo (NMXAA-029-SCFI-2001), alcalinidad (NMX-AA036-SCFI-2001), grasas y aceites (NMX-AA005-SCFI-2013), sulfuros (PROY-NMX-AA084-SCFI-2005) y sulfatos (NMX-AA-074SCFI-2014) en muestras de entrada y salida; en diferentes momentos.

\section{Sistemas de tratamiento}

Se acondicionó como RAFA un equipo piloto ya existente de cultivo bacteriano en medio anaerobio, ubicado en la Universidad Tecnológica de León (Figura 1), con las características indicadas en la Tabla 1.
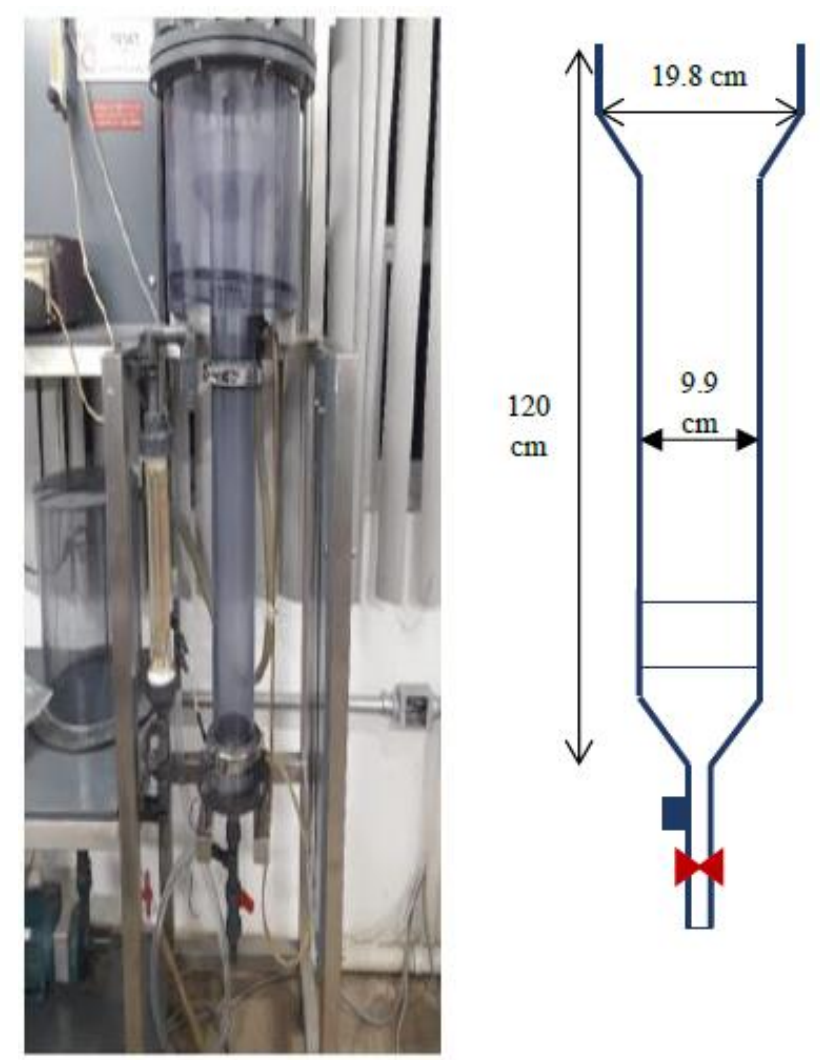

Figura 1 Equipo para cultivo bacteriano en condiciones anaerobias, adaptado como RAFA

\begin{tabular}{|l|r|}
\hline \multicolumn{1}{|c|}{ Material } & \multicolumn{1}{c|}{ Acrílico } \\
\hline Grosor de pared & $5 \mathrm{~mm}$ \\
\hline Diámetro interno de la columna & $0.099 \mathrm{~m}$ \\
\hline Altura total & $1.2 \mathrm{~m}$ \\
\hline Volumen total & $0.0082 \mathrm{~m}^{3}$ \\
\hline
\end{tabular}

Tabla 1 Características del equipo piloto adaptado como RAFA

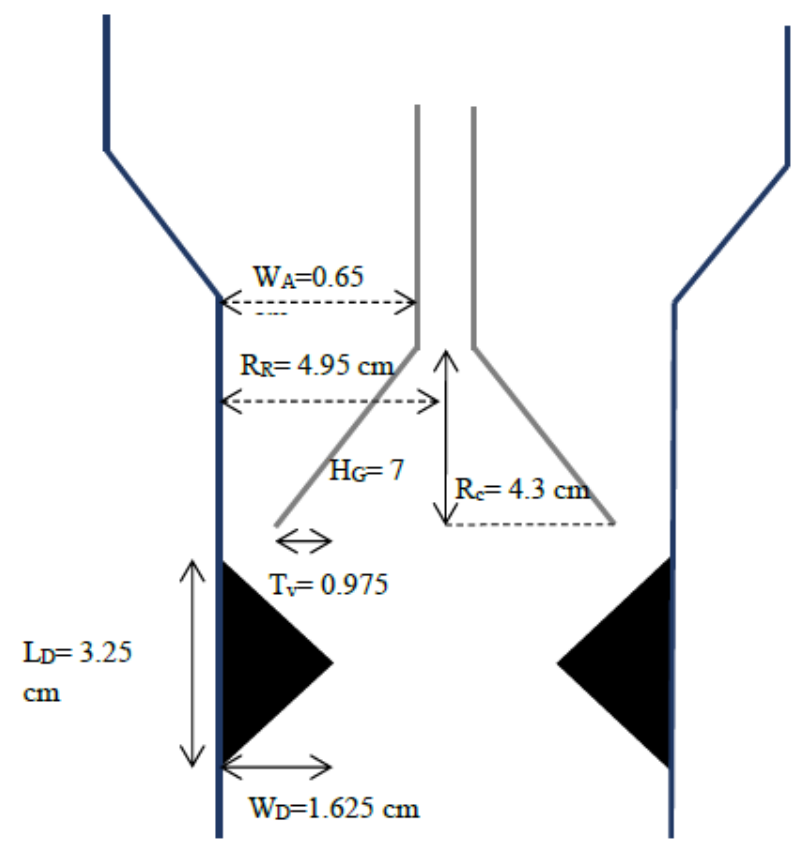

Figura 2 Equipo para cultivo bacteriano en condiciones anaerobias que se adaptó como $\mathrm{R}$

Con esta información, se calculó el área del reactor, la altura efectiva, la carga hidráulica, la velocidad de flujo en la campana y el diseño de la campana de separación líquido-gas-sólido. La información de ésta última parte, se presenta en la Figura

Se inoculó el reactor con lodo proveniente de un reactor RAFA de una empresa similar (49133 mgSSV/L), logrando una concentración inicial dentro del equipo piloto, de $35000 \mathrm{mgSSV} / \mathrm{L}$. Se trabajó con un gasto promedio de agua residual de $0.264 \mathrm{~L} / \mathrm{h}$, para tener un tiempo de retención hidráulico de 27.14 h y una carga orgánica volumétrica de $5.09 \mathrm{kgDQO} / \mathrm{m}^{3} \mathrm{~d}$, valores similares al reactor real. En la Figura 3 se presenta el lodo granular usado como inóculo.

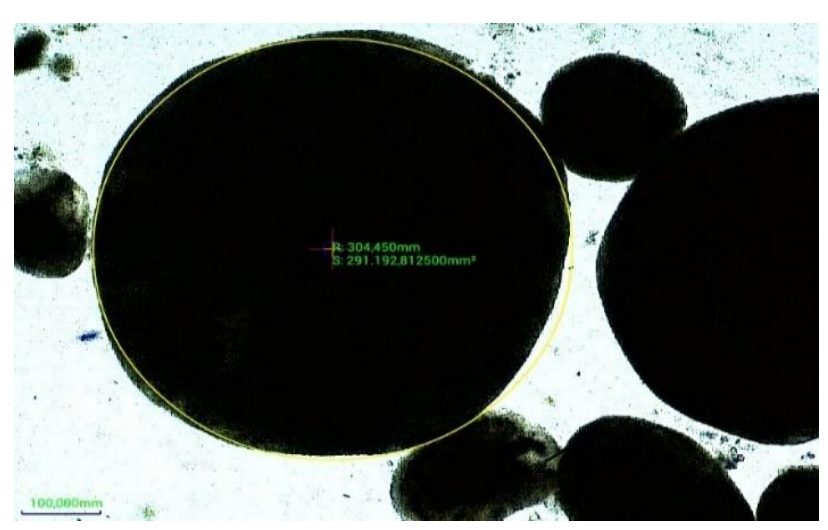

Figura 3 Vista de gránulos de lodo al microscopio 
El sistema piloto de reactor anaerobio de flujo ascendente constó de un tanque de agua residual, de donde el agua era enviada por medio de una bomba hacia el RAFA piloto, para posteriormente salir hacia un tanque de almacenamiento del agua tratada. Los gases, fueron conducidos a un sistema simple de desplazamiento de líquido, para su medición. El diagrama de la configuración del sistema se muestra a continuación (Figura 4) (Balderas Salas \& Cordoba Castro, 2018).

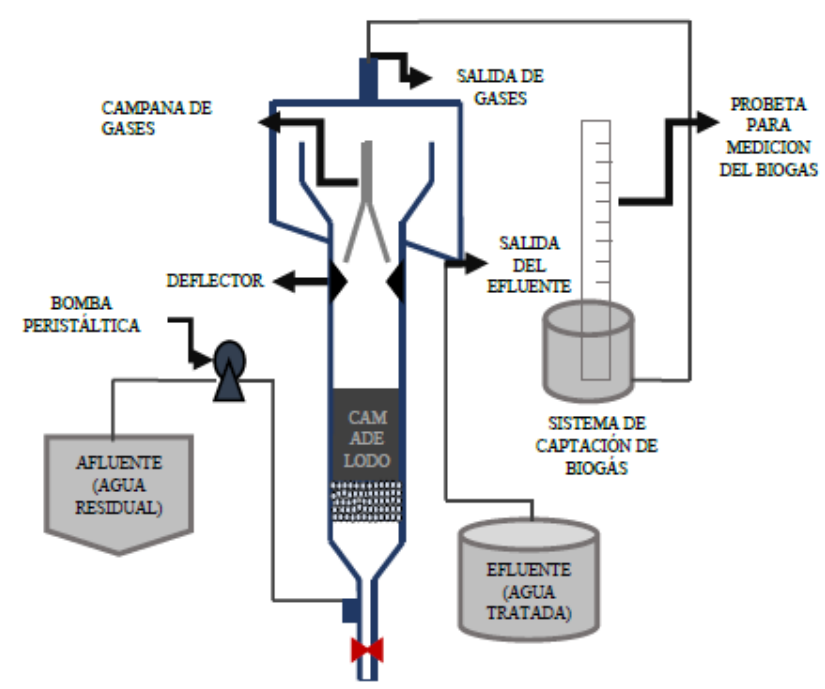

Figura 4 Configuración del sistema piloto, RAFA

La alimentación al reactor se hizo mediante una bomba peristáltica marca Watson Marlow modelo 313S, la cual permitió dosificar y mantener un caudal constante de agua residual al reactor. La bomba enviaba el flujo por la parte inferior de la columna y así, el flujo ascendía de forma constante, haciendo que el agua residual se pusiera en contacto con el manto de lodos de forma uniforme.

\section{Resultados}

Al inicio, el reactor piloto RAFA, fue alimentado con agua residual diluida al 30, $50 \mathrm{y}$ $70 \%$, para permitir la adaptación de la biomasa, logrando remociones de DQO de hasta $64 \%$. Una vez que se alimentó el reactor con agua residual al 100\%, inició el monitoreo del tratamiento, por un periodo de 10 semanas. Se analizó DQO y alcalinidad 3 veces por semana; nitrógeno, fósforo, sulfuros, sulfatos y sólidos 1 vez por semana; grasas y aceites 2 veces por mes y $\mathrm{DBO}_{5}$, al inicio y al final. Desde la segunda semana de monitoreo, se apreció diferencia entre el agua de entrada y el agua de salida del sistema (Figura 5); como la mayor claridad del agua de salida.

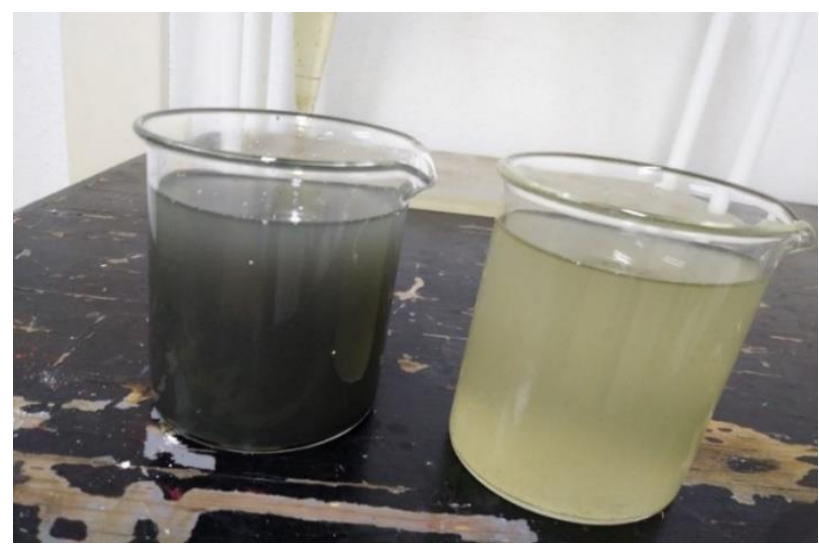

Figura 5 Comparación cualitativa de antes y después del tratamiento, del agua en el reactor piloto RAFA

\section{Demanda química de oxígeno (DQO) y Demanda bioquímica de oxígeno (DBO)}

Se obtuvo una eficiencia de remoción de DQO y $\mathrm{DBO}_{5}$, entre el 65 al $75 \%$ como se muestra en la Gráfica 1; con un valor promedio de $65.24 \%$.

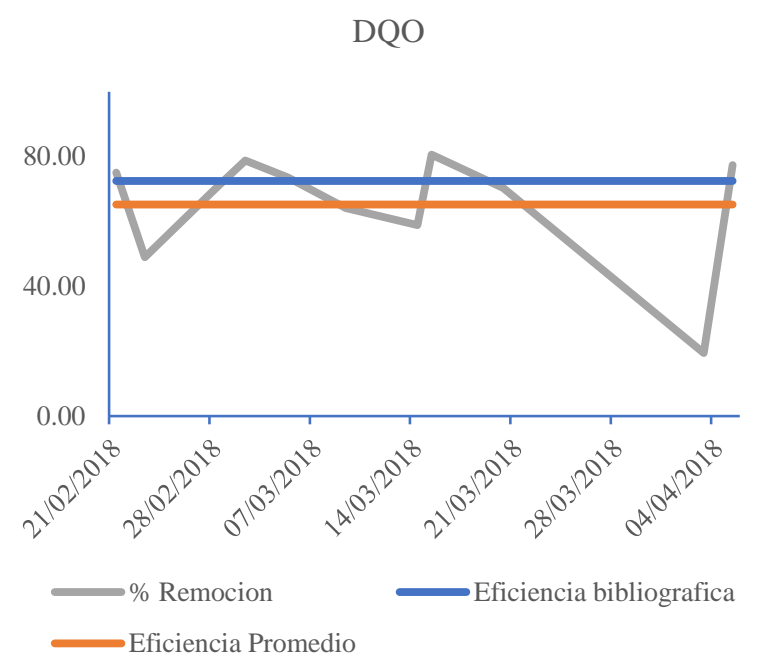

Gráfica 1 Comportamiento de la remoción de DQO

En relación a la $\mathrm{DBO}_{5}$, parámetro importante para el proceso anaerobio, que representa la cantidad de materia orgánica degradable por una población de microorganismos; el reactor presentó una eficiencia de remoción promedio del 52.94\%; obteniendo un agua tratada con una relación $\mathrm{DBO}_{5} / \mathrm{DQO}$ del 69.62\%; valor que indica que el efluente es tratable mediante procesos biológicos (Quispe Livisi, 2014), su valor de entrada fue de $3296 \mathrm{mg} / \mathrm{L}$ y a la salida, de 1551 $\mathrm{mg} / \mathrm{L}$. 


\section{Sólidos}

Los sólidos totales (ST), están compuestos por material orgánico e inorgánico que representan la totalidad de los contaminantes, ya sea en forma disuelta o suspendida Se obtuvo una remoción promedio de sólidos totales del 59.26\%; principalmente de sólidos volátiles, con un valor de $69.3 \%$. El material inorgánico presenta el riesgo de poder acumularse en el sistema y tener efectos negativos en el sistema (Reyes Pantoja, 2009). La conductividad, cuyos valores de entrada y salida fueron muy similares, de $7.7 \mathrm{mS} / \mathrm{cm}$ y $7.24 \mathrm{mS} / \mathrm{cm}$ respectivamente; confirman la poca remoción de material inorgánico.

\section{Nitrógeno}

El nitrógeno total se considera, junto con el fósforo, como un macronutriente para el crecimiento de biomasa; está compuesto por nitrógeno amoniacal, orgánico, nitratos y nitritos. Sin embargo, la forma amoniacal del nitrógeno $\left(\mathrm{N}-\mathrm{NH}_{4}{ }^{+}\right)$, generada de la degradación anaerobia de compuestos orgánicos nitrogenados tales como proteínas y aminoácidos, que se encuentran presentes en el agua de alimentación del reactor piloto, se considera un compuesto tóxico. En relación a este macronutriente, se tuvo una baja remoción, con un valor promedio del $15 \%$. Su valor final promedio fue de $1024 \mathrm{mg} / \mathrm{L}$, que puede resultar inhibitorio del proceso (Márquez Vázquez \& Martínez González, 2011).

\section{Alcalinidad}

La alcalinidad es un parámetro que permite conocer la capacidad del sistema para amortiguar estos cambios de $\mathrm{pH}$. Un elemento relacionado, es el factor $\alpha$; relación entre la alcalinidad de bicarbonatos y la alcalinidad total; para el cual, en reactores anaerobios, se recomiendan valores superiores a 0.5 durante el arranque y de 0.7 en condiciones de estabilidad (Pérez \& Rojas, 2008). Los valores promedio, a la salida del sistema piloto; alcalinidad de 1814 y $\alpha$ de 0.47 muestran que el reactor tiene una capacidad amortiguadora estable.

\section{Sulfuros y sulfatos}

Un compuesto relacionado, el sulfuro de hidrógeno, es inhibitorio; en ciertos niveles de concentración.
Este compuesto se produce durante el proceso anaerobio, lo que indica que aún si los niveles en el influente no son tóxicos, dentro del reactor pueden aumentar (Reyes Pantoja, 2009), producto de la reducción de los sulfatos que se encuentran en el efluente. Se obtuvieron, para sulfatos y sulfuros, los siguientes valores

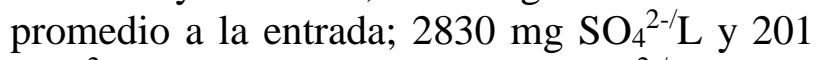
$\mathrm{mgS}^{2-} / \mathrm{L}$; a la salida, $1270 \mathrm{mg} \mathrm{SO}_{4}{ }^{2-/} \mathrm{L}$ y 461 $\mathrm{mgS}^{2-} / \mathrm{L}$ (Tabla 2). Se reportan como valores inhibitorios, concentraciones entre 200 y 1200 $\mathrm{mg} / \mathrm{L}$ (Almeida et al. 2011).

\begin{tabular}{|l|r|r|l|r|r|}
\hline \multicolumn{3}{|c}{ Sulfatos (mg/L) } & \multicolumn{3}{c|}{ Sulfuros $(\mathrm{mg} / \mathrm{L})$} \\
\hline & Entrada & Salida & & Entrada & Salida \\
\hline $22 / 02 / 2018$ & 3000 & 2060 & $02 / 03 / 2018$ & 188 & 600 \\
\hline $27 / 02 / 2018$ & 2545 & 1670 & $06 / 03 / 2018$ & 188 & 415 \\
\hline $06 / 03 / 2018$ & 3220 & 1140 & $09 / 03 / 2018$ & 146 & 483 \\
\hline $14 / 03 / 2018$ & 3480 & 1480 & $20 / 03 / 2018$ & 243 & 385 \\
\hline $21 / 03 / 2018$ & 1905 & 0 & $04 / 04 / 2018$ & 240 & 426 \\
\hline Promedio & 2830 & 1270 & Promedio & 201 & 461 \\
\hline
\end{tabular}

Tabla 1 Concentración de sulfatos y sulfuros del reactor piloto

El reactor piloto funcionó bien, como lo ha mostrado la información referida; por lo que se recomienda aplicar las condiciones de operación trabajadas a los reactores reales. Se recomienda cuidar que haya una concentración adecuada de sólidos suspendidos, mayor a 35 $\mathrm{Kg} / \mathrm{m}^{3}$, inoculando con lodo anaerobio proveniente de otros reactores similares y monitorear la evolución de la biomasa, para evitar pérdida de la misma en el sistema,

\section{Conclusiones}

El tratamiento anaerobio del agua residual, de la empresa productora de grenetina, mediante un reactor piloto anaerobio de flujo ascendente, es viable, pues se alcanzó una eficiencia de remoción de DQO promedio del $65.24 \%$; operando con la misma condición de tiempo de retención hidráulico de $27.14 \mathrm{~h}$ del reactor real, para un flujo de $14.58 \mathrm{~L} / \mathrm{s}$. Cualitativamente se pudo apreciar que el agua tratada cambio de apariencia, de una coloración grisácea y con nula claridad, a amarillenta con poca transparencia y sin sólidos. En fósforo y grasas y aceites, no hubo cambios importantes. La observación al microscopio del lodo granular, mostró que tenía coloración negra y una consistencia granular, bien definida. 
Su caracterización inicial, indicó una concentración de sólidos totales de 126060 $\mathrm{mg} / \mathrm{L}$, con un $41.37 \%$ de fracción orgánica $(52160 \mathrm{mg} / \mathrm{L})$. El valor de la concentración en el lodo inoculado, fue de $49133 \mathrm{mgSS} / \mathrm{L}$, lo cual indicó su viabilidad para ser usado como inóculo.

Los valores de $\mathrm{pH}$ promedio del sistema piloto a la entrada, 7.2 y a la salida, 8 , muestran que el proceso tiene una capacidad amortiguadora, confirmado con el valor promedio del factor alfa de 0.47 , cercano al intervalo recomendado, entre 0.5 y 0.7 .

El sistema de tratamiento tiene compuestos, que pueden resultar tóxicos, como el nitrógeno amoniacal y sulfatos. Sin embargo, la eficiencia del tratamiento no resultó afectada; mismo comportamiento que es de esperar en el sistema real.

\section{Agradecimientos}

Agradecemos a la Universidad Tecnológica de León y a la empresa productora de grenetina, de León, Guanajuato, México; por su apoyo y colaboración, que hicieron posible la realización del presente proyecto.

\section{Referencias}

Almeida, A., Nafarrate-Rivera, E., Alvarado, A., A., C.-O., Luevanos, M., R., O., \& Balagurusamy, N. (2011). Expresión genética en la digestión anaerobia: un paso adelante en la comprensión de las interacciones tróficas de esta biotecnología. Acta Química Mexicana, 3(6), 14-34.

Balderas Salas, P. S. (2016). Propuesta de mejora para el reactor anaerobio de flujo ascendente de empresa productora de grenetina. León, Guanajuato, México.

Balderas Salas, P. S., \& Cordoba Castro, A. L. (2018). Tratamiento biológico en reactor anaerobio de flujo ascendente de empresa productora de grenetina. León, Guanajuato, México: UTL.

CNA. (2017). Estadísticas del Agua en México. Edición 2017. México: CNA.

CNA. (2018). Estadísticas del Agua en México 2018. México: CNA.
Larrota, L., García, L., \& Torrres, L. y. (2019). Análisis de la eficiencia de reactores UASB en una planta de tratamiento de aguas residuales municipales. 86(209), 319-326.

Lorenzo Acosta, Y., \& Obaya Abreu, M. C. (2005). La digestión anaerobia. Apectos teóricos. Parte I. ICIDCA Instituto cubano de investigaciones de los derivados de la caña de azúcar, XXXIX(1), 35-48.

Márquez Vázquez, M., \& Martínez González, S. (2011). Reactores anaerobios de flujo ascendente (RAFA's o UASCB) antología. México: UNAM.

Montoya, D. I., Rincones, M. E., Najul, M. V., Blanco, H. A., López, E. E., Sánchez, R., . . . Regina, M. (2003). Experiencias a escala piloto en sistemas UASB para tratamiento de aguas residuales municipales en Venezuela. Revista de la Facultad de Ingeniería de la U.C.V., 18(1), $33-44$.

Mora, E., \& A.M., M. (2019). Tipología de las tecnologías de tratamiento de aguas residuales ordinarias instaladas en Costa Rica. Revista de Ciencias Ambientales, 53(2), 97-110.

Pachuca Guerra, R. C. (2015). Optimización del sistema de tratamiento de agua. León, Guanajuato, México.

Parra Orobio, B. A. (2014). Producción de metano a partir de la digestión anaerobia de biorresiduos de origen municipal. Cali, Colombia: Universidad del Valle.

Pérez, A., \& Rojas, P. (2008). Indices de alcalinidad para el control del tratamiento anaerobio de aguas residuales fácilmente acidificables. Cali, Colombia: Universidad del Valle.

Quispe Livisi, J. A. (2014). Estudio de la remoción de carga orgánica en un reactor anaerobio de manto de lodo de flujo ascendente con digestor de lodos aplicado a una localidad ubicado a una altitud de 3800 msnm". Lima, Perú: Universidad Nacional de Ingeniería.

Reyes Pantoja, M. D. (2009). Tratamiento de aguas residuales provenientes de rastro mediante un sistema de biodegradacion anaerobia-aerobia. Ciudad de México: UNAM. 
Rubens Sette Ramalho, D. J. (1996). Tratamiento de aguas residuales. Barcelona: EDITORIAL REVERTÉ, S. A.

Sosa Villalobos, C. (2014). Arranque de un reactor anaerobio, con aguas residuales de destilería de alcohol de caña. Revista Iberoamericana de Ciencias, 1(5), 199-207.

Tapia, S., Vela, R., Miglio, R., Quipuzco, L., Juscamaita, J., \& Álvarez, C. (2019). Puesta en marcha de un reactor UASB para el tratamiento de aguas residuales de la crianza intensiva de cerdos. Agroindustrial Science, 8(2), 137-145.

Torres Lozada, P., \& Pérez, A. (2010). Actividad metanogénica específica: una herramienta de control y optimización de sistemas de tratamiento anaerobio de aguas residuales. Ingeniería de Recursos Naturales y del Ambiente(9), 5-14.

Torres, P. (2012). Perspectivas del tratamiento anaerobio de aguas residuales dométicas en países en desarrollo. EIA.Esc. Ing.Antioq(18), 115-119. 